\title{
Comparison between bilateral implantation of a trifocal intraocular lens and blended implantation of two bifocal intraocular lenses
}

This article was published in the following Dove Press journal:

Clinical Ophthalmology

I August 2017

Number of times this article has been viewed

\author{
César Vilar ${ }^{1,2}$ \\ Wilson Takashi Hida ${ }^{1-3}$ \\ André Lins de Medeiros 1,2 \\ Klayny Rafaella Pereira \\ Magalhães ${ }^{2}$ \\ Patrick Frensel de Moraes \\ Tzelikis ${ }^{1,2}$ \\ Mario Augusto Pereira Dias \\ Chaves ${ }^{2,4}$ \\ Antônio Francisco Pimenta \\ Motta $^{2,3}$ \\ Pedro Carlos Carricondo ${ }^{1-3}$ \\ Milton Ruiz Alves ${ }^{3}$ \\ Walton Nosé ${ }^{5}$ \\ 'Cataract Division, Brasília \\ Ophthalmologic Hospital (HOB), \\ Brasília-DF, Brazil; ${ }^{2}$ Renato Ambrosio \\ Ophthalmologic Research Center \\ (CEORA), ${ }^{3}$ Ophthalmology \\ Department, São Paulo University - \\ USP, São Paulo-SP, Brazil; ${ }^{4}$ Cataract \\ Division, ProVisão, João Pessoa-PB, \\ Brazil; ${ }^{5}$ Ophthalmology Department, \\ Paulista Medical School - UNIFESP, \\ São Paulo-SP, Brazil
}

Correspondence: César Vilar Rua Benjamin Constant 2290, Teresina-PI, Postal code 64000-280, Brazil

Tel +55 8621079900

Email cesar.vilar@gmail.com
Purpose: To compare visual outcomes and performance between bilateral implantation of a diffractive trifocal intraocular lens (IOL) Acrysof ${ }^{\circledR}$ PanOptix ${ }^{\circledR}$ TFNT00 and blended implantation of two different near add power bifocal IOLs: Acrysof ${ }^{\mathbb{B}}$ Restor $^{\circledR}$ SV25T0 in dominant eye and Acrysof ${ }^{\circledR}$ Restor $^{\circledR}$ SN6AD1 in the nondominant eye.

Methods: This prospective, nonrandomized, consecutive and comparative study assessed 20 patients (40 eyes) who had bilateral cataract surgery performed using the IOLs described. Patients were divided into groups, bilateral trifocal implant and blended implant. Evaluation included measurement of binocular uncorrected and corrected distance visual acuity at $4 \mathrm{~m}$ (UDVA, CDVA) and uncorrected intermediate $(60 \mathrm{~cm}$ ) and near (at $40 \mathrm{~cm}$ ) visual acuity; contrast sensitivity (CS) and visual defocus curve.

Results: Postoperative CDVA comparison showed no statistical significance between groups. UDVA was significantly better in the trifocal groups. Under photopic conditions, the trifocal group had better CS in higher frequencies with and without glare. The binocular defocus curve demonstrated a trifocal behavior in both groups, with the bilateral trifocal group exhibiting better performance for intermediate vision.

Conclusion: Both lens combinations were able to provide good near, intermediate and distance vision, with the trifocal group showing significantly better performance at intermediate distances and better CS under photopic conditions.

Keywords: trifocal, blend, cataract surgery, IOL, multifocal, presbyopia

\section{Introduction}

Intraocular lenses (IOLs) replace the dioptric power of the lens after cataract surgery. Traditional IOLs are the monofocals that have a single focal length being able to provide good visual function to the patient and can correct ametropias to improve distance vision. ${ }^{1}$ However, pseudophakic patients with monofocal IOLs end up needing glasses to compensate for the loss of accomodation. ${ }^{2,3}$

Multifocal IOLs offer the patient an opportunity to correct the effects of presbyopia after cataract surgery. Despite the optical evolution and technology in lens manufacture, possible side effects of multifocal IOLs include glare, halos and other dysphotopsias; reduced contrast sensitivity $(\mathrm{CS})$ and unsatisfactory uncorrected visual acuity. ${ }^{4,5}$

Most commercially available multifocal IOLs have two optical zones: one that provides distance vision and the second that provides near vision, known as bifocal IOLs. ${ }^{6}$ More recently, trifocal IOLs have been released, providing a third intermediate focal point. As an even greater division of light occurs to create one more focus, there is concern about the increase in undesirable optical phenomena 
with trifocal lenses. ${ }^{7}$ Some studies have already shown that improved vision at intermediate distances is created at the expense of worsening far and near vision quality. ${ }^{8}$ The greatest challenge of multifocal IOLs is to provide good vision quality at all distances while minimizing undesirable phenomena. ${ }^{9}$

Acrysof ${ }^{\circledR}$ IQ Restor ${ }^{\circledR}$ (SV25T0 and SN6AD1) (Alcon Laboratories, Inc., Forth-Worth, TX, USA) IOLs have, respectively, near addition power of +2.5 and +3.0 diopters in the IOL plane. These are two diffractive bifocal lenses with apodized design in the anterior surface. Usually, they are implanted bilaterally providing good visual acuity at far and near (50 and $40 \mathrm{~cm}$, respectively) distances. However, the patient is likely to experience some limitation to see clearly at distances other than that determined by the IOL's focal points. The SV25T0 demonstrated a lower incidence of visual disturbances in comparison with SN6AD1. Some surgeons associate the characteristics of each lens by performing the contralateral (also known as a "blended") implant strategy, which consists of implanting SV25T0 IOL in the dominant eye and SN6AD1 in the nondominant eye. It has already been shown that this technique is able to increase the useful range of near vision. ${ }^{9,10}$

The Acrysof IQ PanOptix (TFNT00) is a trifocal IOL made of hydrophobic acrylic. It has a trifocal nonapodized design and provides a near sight point at $40 \mathrm{~cm}$ and far sight similar to the SN6AD1 model, presenting the additional benefit of an intermediate focal point of $60 \mathrm{~cm} .{ }^{11,12}$

At our center, the blended implantation is done as routine in patients requiring improved intermediate vision. With the availability of trifocal IOLs, there is a need for comparison between the two strategies.

The purpose of this study is to compare the visual results of near, intermediate and far vision, CS and the defocus curve between SV25T0 (dominant eye) and SN6AD1 (nondominant eye) blended implantation and the bilateral TFNT00 (Alcon Laboratories, Inc.) implantation.

\section{Methods}

This study was conducted in accordance with the ethics principles of the Declaration of Helsinki and was approved by the Brasília Ophthalmologic Hospital Ethics Research Committee, Brasília, Brazil.

This was a prospective, nonrandomized, comparative study of consecutive cases.

The study involved 20 subjects, 15 females (75\%) and five males (25\%). Patient characteristics are summarized in Table 1.
Table I Demographic characteristics of patients by group

\begin{tabular}{llll}
\hline & Trifocal & Blend & $P$-value \\
\hline $\begin{array}{l}\text { Gender } \\
\text { (male/female) }\end{array}$ & $2 / 10$ & $4 / 10$ & 0.35 \\
Age, years & $64.2 \pm 8.34(5 I-70)$ & $61.9 \pm 4.45(56-7 I)$ & 0.32 \\
Pre-CDVA & $0.24 \pm 0.18(0.54-0.00)$ & $0.15 \pm 0.13(0.44-0.00)$ & 0.073 \\
\hline
\end{tabular}

Note: Data are shown as mean \pm SD (lower bound-upper bound).

Abbreviation: Pre-CDVA, preoperative corrected distant visual acuity.

All patients underwent an uneventful cataract surgery followed by IOL implantation by a single surgeon (W.T.H) between July 2016 and October 2016. Surgery of the second eye was performed within 30 days of the first. Informed consent was obtained from all patients prior to data collection. Analysis of the optical function and CS was performed and compared between the bilateral implantation of TNFT00 and the blended implantation of SV25T0 in the dominant eye and the SN6AD1 in the nondominant eye. Exclusion criteria were, 1) existence of any corneal, retinal or optic nerve disease, 2) previous eye surgery, 3) illiteracy, 4) previous corneal refractive surgery, 5) high axial myopia, 6) postoperative corneal astigmatism of $>1.00$ cylindrical diopter (D), and 7) intraoperative or postoperative complications.

All patients underwent complete preoperative and 1-month (after second eye surgery) postoperative ophthalmological examination, including biomicroscopy, tonometry, retinoscopy, fundoscopy, near, intermediate and far visual acuity, defocus curve and CS. Uncorrected near (UNVA, $40 \mathrm{~cm}$ ), uncorrected intermediate (UIVA, $60 \mathrm{~cm}$ ) and corrected and uncorrected distance (CDVA, UDVA, 4 $\mathrm{m})$ binocular visual acuity were measured using the Early Treatment Diabetic Retinopathy Study reading charts (ETDRS; Vector Vision, Ltd, Greenville, OH, USA and Precision Vision, IL, USA).

The evaluation included the testing of binocular CS under photopic and mesopic conditions (with and without glare) using the CSV-1000 chart (Vector Vision, Inc., Greenville, $\mathrm{OH}, \mathrm{USA}$ ) with spatial frequencies ranging between 1.5 and 18 cycles/degree $(\mathrm{cpd})$ at $2.5 \mathrm{~m}$. Glare was generated from CSV-1000's halogen lamps and set at the factory-calibrated level automatically. A table provided by the manufacturer was used to convert the data into base 10 logarithms for statistical analysis.

Binocular defocus curves were obtained in corrected distance visual acuity with the same ETDRS charts, at intervals of 0.50 spherical diopters from -5.00 to $0.00 \mathrm{D}$. Levels of luminance were measured using Gossen starlite 2 (Gossen, Nürnberg, Germany). Photopic conditions were defined 
Table 2 Descriptive measures for implanted IOL refractive power (diopters), postoperative, spherical equivalent, postoperative visual acuities and pupillometry for Trifocal and Blend groups

\begin{tabular}{|c|c|c|c|}
\hline \multirow[t]{2}{*}{ Measurement } & \multicolumn{2}{|l|}{ Mean \pm SD (min-max) } & \multirow[t]{2}{*}{$P$-value } \\
\hline & Trifocal $(n=20)$ & Blend $(n=20)$ & \\
\hline IOL diopter & $22.23 \pm I .5 \mathrm{I}(20.00-25.50)$ & $21.30 \pm 1.38(19.00-23.50)$ & 0.123 \\
\hline UDVA & $0.0 \mathrm{I} \pm 0.04(-0.04$ to 0.10$)$ & $0.08 \pm 0.05(-0.02$ to 0.16$)$ & $<0.01 *$ \\
\hline UIVA & $0.14 \pm 0.05(0.06-0.22)$ & $0.22 \pm 0.06(0.12-0.34)$ & $<0.01 *$ \\
\hline UNVA & $-0.03 \pm 0.04(-0.1$ to 0.06$)$ & $0.07 \pm 0.03(0.04-0.12)$ & $<0.01 *$ \\
\hline SE & $-0.07 \pm 0.23(-0.50$ to 0.25$)$ & $0.03 \pm 0.19(-0.38$ to 0.38$)$ & 0.226 \\
\hline CDVA & $0.01 \pm 0.06(-0.10$ to 0.16$)$ & $0.04 \pm 0.06(-0.06$ to 0.14$)$ & $<0.0 I^{¥}$ \\
\hline Pupillometry (mesopic) & $4.78 \pm 0.64(3.50-5.50)$ & $5.08 \pm 0.75(3.50-6.0)$ & 0.423 \\
\hline
\end{tabular}

Notes: ${ }^{*}=$ analysis of variance; $*=$ Kruskal-Wallis.

Abbreviations: CDVA, postoperative corrected distance visual acuity; IOL, intraocular lens; SE, postoperative spherical equivalent; UDVA, postoperative uncorrected distance visual acuity; UIVA, postoperative uncorrected intermediate visual acuity; UNVA, postoperative uncorrected near visual acuity.

as $\sim 85$ candelas $/$ meter $^{2}\left(\mathrm{~cd} / \mathrm{m}^{2}\right)$ and ambient luminance was defined as inferior to 21.25 lux.

Significance was tested using the analysis of variance and Tukey's test for parametric variables and Kruskal-Wallis test for nonparametric variables, adjusting to a level of significance of $5 \%(P<0.05)$ and using software $\mathrm{R}$ version 3.3.2 for analysis (Foundation for Statistical Computing, Vienna, Austria).

\section{Results}

All patients were submitted to the second eye surgery after 1 week and before 30 days of the first surgery. Average time interval was 11 days (8-22 days) in the trifocal group and 12 days (8-28) for the blend group. There were no significant differences between the two groups $(P>0.5)$.

Average preoperative CDVA was better in the blend group than in the trifocal group ( 0.24 vs $0.15 \log$ MAR, $P=0.073$ ), although this difference was not statistically significant (Table 1). Groups achieved homogeneity in age, gender, IOL diopter and postoperative spherical equivalent (SE) (Tables 1 and 2).

The trifocal group showed better results for CS under photopic conditions at $6(P=0.046), 12(P<0.01)$ and $18 \mathrm{cpd}(P<0.01)$ without glare. At $3 \mathrm{cpd}$ there was no statistically significant difference. With glare, there were no significant differences between groups at 3, 6 and $12 \mathrm{cpd}$. At $18 \mathrm{cpd}$, the trifocal group showed better CS $(P<0.01)$ (Figures 1 and 2).

Under mesopic conditions without glare there was no significant difference in CS between groups. With glare, the blend group performed better at $3(P<0.01), 6(P=0.014)$ and $12 \mathrm{cpd}(P<0.01)$. At $1.5 \mathrm{cpd}$, the trifocal group showed better CS $(P=0.023)$ (Figures 3 and 4$)$.

Defocus curves in the two groups achieved a trifocal pattern, with the trifocal group achieving statistically significant better visual acuity from $-2.00 \mathrm{D}$ to plano and at -3.50 (Figure 5).

\section{Discussion}

Our results show that both the trifocal bilateral implantation and the blended implantation strategies are capable of achieving good CDVA, UIVA and UNVA as demonstrated in other studies comparing other trifocal lenses. ${ }^{13-15}$ As postoperative SE approached emmetropia and was not significantly different between groups, both treatments have shown efficacy and provided independence from glasses.

Analysis of CDVA, UDVA, UIVA and UNVA highlighted advantages of the PanOptix bilateral implant $(P<0.05)$ in our study. In a recently published study comparing FineVision and PanOptix, the authors demonstrated a very good performance of both IOLs with no difference in distance vision. At $80 \mathrm{~cm}$, FineVision patients had better VA. From $60 \mathrm{~cm}$ and nearer PanOptix showed better results with a defocus curve very similar to our study. ${ }^{16}$ Studies conducted on different commercial models of trifocal IOLs have reported good distance, intermediate and near VAs.

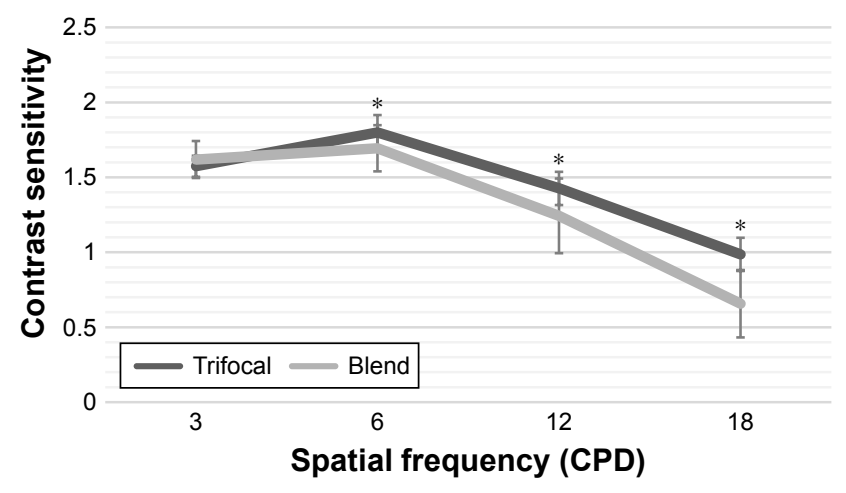

Figure I Binocular photopic contrast sensitivity without glare. Note: $* P<0.01$. 


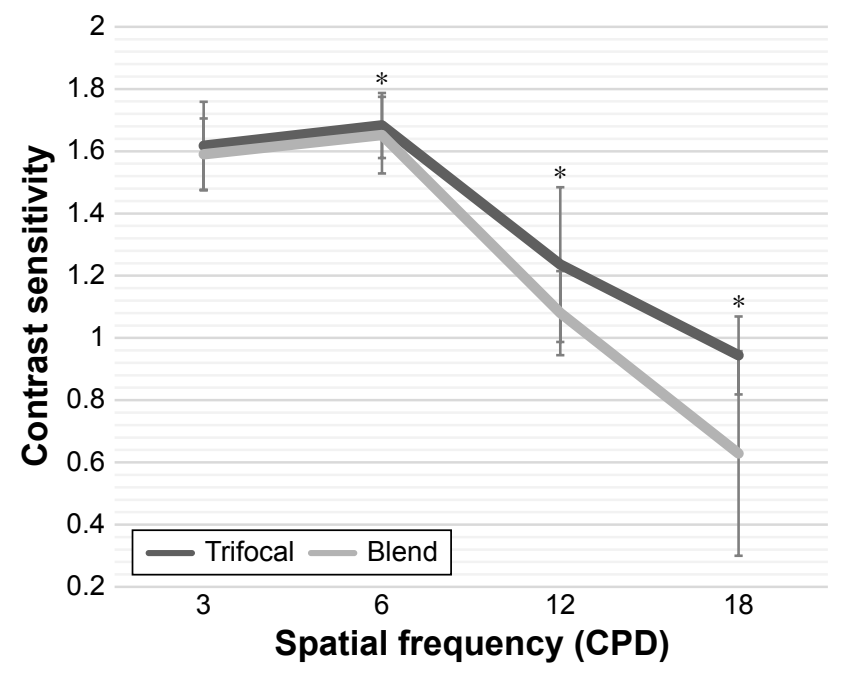

Figure 2 Binocular photopic contrast sensitivity with glare. Note: $* p<0.05$.

In a study reporting 44 eyes of 22 patients implanted with FineVision (PhysIOL, Liège, Belgium) trifocal IOL, a full range of adequate vision was achieved, CS was satisfactory and there were no significant adverse photic phenomena after implantation. ${ }^{17}$ In 54 eyes of 27 patients who underwent AT LISA trifocal IOL implantation following phacoemulsification, good distance, intermediate and near VAs $(0.10$ $\log$ MAR or better), a high patient satisfaction and a high spectacle independence were reported. ${ }^{18}$

Some publications have reported great visual outcomes with the blended strategy. Gundersen and Potvin ${ }^{8}$ compared the blend strategy against bilateral FineVision trifocal IOL. Although there were no significant differences in near, intermediate or distant corrected VAs, four points of defocus curves showed significant dominance of the trifocal IOL. Nuijts et al compared the blend with the bilateral implantation of SV25T0, achieving similar results between groups, with

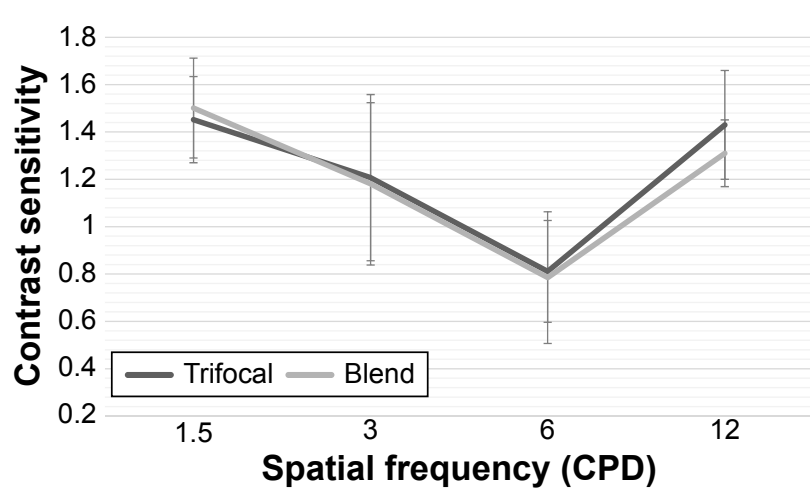

Figure 3 Binocular mesopic contrast sensitivity without glare.

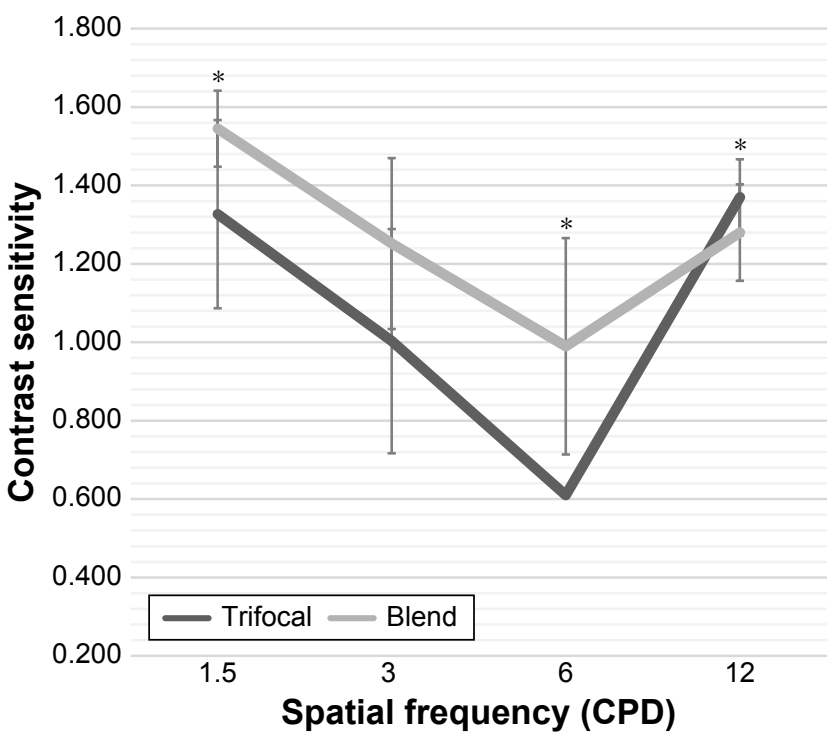

Figure 4 Binocular mesopic contrast sensitivity with glare. Note: $* P<0.05$.

better, but not statistically significant, average VA at near distance for the blended group. In both studies, defocus curves of the blended group were very similar to our study. ${ }^{8,9}$

The trifocal group showed excellent visual acuity through a considerably big interval of vergence $(-0.1$ and +0.1 $\operatorname{logMAR}$ from -2.50 to plano), suggesting that this strategy could have a better tolerance of a hyperopic residual refraction error when compared to the blended implantation.

In the present study, the best levels of photopic CS were achieved at $6 \mathrm{cpd}$ (Figures 1 and 2). The trifocal group showed statistically significantly better performance in CS without glare. When we analyze at mesopic condition, the highest levels of CS were seen in the lowest frequencies

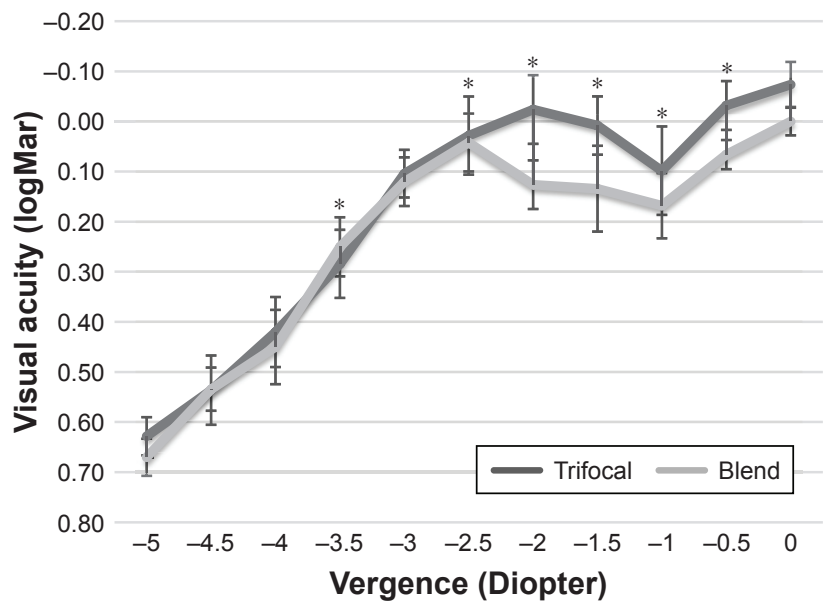

Figure 5 Binocular distance-corrected defocus curve. Note: $* P<0.05$. 
(1.5 and $3.0 \mathrm{cpd}$ ) in both groups. Without glare, there was no statistically significant difference between groups. With glare, the blend group was better at 1.5, 3.0 and $6 \mathrm{cpd}$ while the trifocal group was better at $12 \mathrm{cpd}$. Nuijts et al have also achieved the highest level of CS at $6 \mathrm{cpd}$, although they have found no statistical significance. ${ }^{9}$ Mastropasqua et al compared the SV25T0/SN6AD1 blend with the bilateral implantation of each lens separately, having found no statistically significant difference between groups and achieved highest $\mathrm{CS}$ at $3 \mathrm{cpd}$. This could be explained by a diminished tendency of dysphotopic phenomena regarding SV25T0. ${ }^{19}$

Limitations of the study include the small number of patients selected, which reduces statistical power of the analysis. In addition, the testing distances applied favor the trifocal group, considering the manufacturer data.

In conclusion, both the strategies were effective in enabling good vision for far, intermediate and short distances with the trifocal group exhibiting better overall performance. More studies are needed to analyze different criteria and to increase the number of patients to improve statistical power.

\section{Disclosure}

The authors report no conflicts of interest in this work.

\section{References}

1. Schuster AK, Tesarz J, Vossmerbaeumer U. The impact on vision of aspheric to spherical monofocal intraocular lenses in cataract surgery: a systematic review with meta-analysis. Ophthalmology. 2013;120(11): 2166-2175.

2. Davidson RS, Dhaliwal D, Hamilton DR, et al. Surgical correction of presbyopia. J Cataract Refract Surg. 2016;42(6):920-930.

3. Javitt J, Brauweiler HP, Jacobi KW, et al. Cataract extraction with multifocal intraocular lens implantation: clinical, functional, and quality-of-life outcomes. Multicenter clinical trial in Germany and Austria. J Cataract Refract Surg. 2000;26(9):1356-1366.

4. Gil-Cazorla R, Shah S, Naroo SA. A review of the surgical options for the correction of presbyopia. Br J Ophthalmol. 2016;100(1):62-70.

5. Chang DH. Visual acuity and patient satisfaction at varied distances and lighting conditions after implantation of an aspheric diffractive multifocal one-piece intraocular lens. Clin Ophthalmol. 2016;10:1471-1477.
6. Gatinel D, Loicq J. Clinically relevant optical properties of bifocal, trifocal, and extended depth of focus intraocular lenses. J Refract Surg. 2016;32(4):273-280.

7. Sheppard AL, Shah S, Bhatt U, Bhogal G, Wolffsohn JS. Visual outcomes and subjective experience after bilateral implantation of a new diffractive trifocal intraocular lens. J Cataract Refract Surg. 2013;39(3): 343-349.

8. Gundersen KG, Potvin R. Comparison of visual outcomes and subjective visual quality after bilateral implantation of a diffractive trifocal intraocular lens and blended implantation of apodized diffractive bifocal intraocular lenses. Clin Ophthalmol. 2016;10:805-811.

9. Nuijts RM, Jonker SM, Kaufer RA, et al. Bilateral implantation of $+2.5 \mathrm{D}$ multifocal intraocular lens and contralateral implantation of +2.5 D and +3.0 D multifocal intraocular lenses: clinical outcomes. $J$ Cataract Refract Surg. 2016;42(2):194-202.

10. Neuhann IM, Kleinmann G, Apple DJ. A new classification of calcification of intraocular lenses. Ophthalmology. 2008;115(1):73-79.

11. Carson D, Xu Z, Alexander E, Choi M, Zhao Z, Hong X. Optical bench performance of 3 trifocal intraocular lenses. J Cataract Refract Surg. 2016;42(9):1361-1367.

12. Chaves MA, Hida WT, Tzeliks PF, et al. Comparative study on optical performance and visual outcomes between two diffractive multifocal lenses: AMO tecnis ${ }^{\circledR}$ ZMB00 and AcrySof ${ }^{\circledR}$ IQ ReSTOR $®$ multifocal IOL SN6AD1. Arq Bras Oftalmol. 2016;79(3):171-176.

13. Jonker SM, Bauer NJ, Makhotkina NY, Berendschot TT, van den Biggelaar FJ, Nuijts RM. Comparison of a trifocal intraocular lens with a +3.0 D bifocal IOL: results of a prospective randomized clinical trial. $J$ Cataract Refract Surg. 2015;41(8):1631-1640.

14. Kretz FT, Choi CY, Müller M, Gerl M, Gerl RH, Auffarth GU. Visual outcomes, patient satisfaction and spectacle independence with a trifocal diffractive intraocular lens. Korean J Ophthalmol. 2016;30(3): 180-191.

15. Mendicute J, Kapp A, Lévy P, et al. Evaluation of visual outcomes and patient satisfaction after implantation of a diffractive trifocal intraocular lens. J Cataract Refract Surg. 2016;42(2):203-210.

16. Gundersen KG, Potvin R. Trifocal intraocular lenses: a comparison of the visual performance and quality of vision provided by two different lens designs. Clin Ophthalmol. 2017;11:1081-1087.

17. Carballo-Alvarez J, Vazquez-Molini JM, Sanz-Fernandez JC, et al. Visual outcomes after bilateral trifocal diffractive intraocular lens implantation. BMC Ophthalmol. 2015;15:26.

18. Kohnen T, Titke C, Böhm M. Trifocal intraocular lens implantation to treat visual demands in various distances following lens removal. Am J Ophthalmol. 2016;161:71-77.e1.

19. Mastropasqua R, Pedrotti E, Passilongo M, Parisi G, Marchesoni I, Marchini G. Long-term visual function and patient satisfaction after bilateral implantation and combination of two similar multifocal IOLs. J Refract Surg. 2015;31(5):308-314.
Clinical Ophthalmology

\section{Publish your work in this journal}

Clinical Ophthalmology is an international, peer-reviewed journal covering all subspecialties within ophthalmology. Key topics include: Optometry; Visual science; Pharmacology and drug therapy in eye diseases; Basic Sciences; Primary and Secondary eye care; Patient Safety and Quality of Care Improvements. This journal is indexed on Submit your manuscript here: http://www.dovepress.com/clinical-ophthalmology-journal

\section{Dovepress}

PubMed Central and CAS, and is the official journal of The Society of Clinical Ophthalmology (SCO). The manuscript management system is completely online and includes a very quick and fair peer-review system, which is all easy to use. Visit http://www.dovepress.com/ testimonials.php to read real quotes from published authors. 